\title{
POLÍTICAS DE ATENDIMENTO À CRIANÇA PEQUENA NOS PAÍSES EM DESENVOLVIMENTO
}

\author{
MARIA CLOTILDE ROSSETTII-FERREIRA
}

Professora titular do Departamento de Psicologia e Educação da Faculdade de Filosofia, Ciências e Letras de Ribeirão Preto - USP - e coordenadora do Centro de Investigações sobre Desenvolvimento Humano e Educação Infantil mcrferre@usp.br

\author{
FABIOLA RAMON \\ Mestranda em Saúde Mental pela Faculdade \\ de Medicina de Ribeirão Preto - USP \\ fabiramon@uol.com.br
}

\section{ANA PAULA SOARES SILVA}

Professora assistente e doutoranda em Psicologia pela Faculdade de Filosofia,

Ciências e Letras de Ribeirão Preto - USP

apssilva@ffclrp.usp.br

As autoras agradecem à Fapesp e ao CNPq por auxílios e bolsas, a Angela Rabelo Barreto por contribuir com referências e fontes de pesquisa, a Fúlvia Rosemberg e Robert Myers por fornecerem manuscritos/originais de conferências recentes. 


\section{RESUMO}

Contínuas mudanças econômicas e culturais estão causando transformações no funcionamento das familias e na educação das crianças pequenas em todas as camadas sociais. Essas transformações têm contribuído para o aumento da demanda e implementação de políticas de educação/cuidado infantil. Avanços politicos e legais têm ocorrido em vários países, nas últimas décadas. Esse processo configura-se sob formas diversas nos países desenvolvidos e nos em desenvo/vimento. Naqueles e, em especial, nos países da Comunidade Européia, as justificativas para essas políticas fundamentam-se em um discurso pelos direitos da criança quanto ao acesso à educação e aos bens culturais, e pela igualdade de direitos e oportunidades de homens e mulheres. Já nos países em desenvolvimento, o discurso para ricos e pobres é bastante diferenciado, particularmente quando estabelece politicas para expansão do atendimento. Quando o alvo é a população pobre, negra e de zona rural, essas politicas se pautam por um discurso da necessidade de atender pobremente a pobreza, que transparece de maneira clara nos documentos do Banco Mundial. Neste artigo, propomo-nos a fazer uma reflexão crítica sobre as politicas para a infância nos países em desenvolvimento, tomando a América Latina como estudo de caso.

POLITICAS EDUCACIONAIS - EDUCAÇÃO INFANTIL - AMÉRICA LATINA - BANCO MUNDIAL

\section{ABSTRACT}

POLICIES FOR EARLY CHILD CARE AND EDUCATION IN DEVELOPING COUNTRIES. Continuous economical and cultural changes are inducing various transformations in family functioning and young children education and care. Those changes generated an increased demand for early child education policies. During the last decades, various political and legal advances were observed in many countries. This process, however, took diverse configurations in developed and developing countries. In the European Community, more specifically, the discourse funding those policies emphasized both: children's rights to have access to education and cultural goods and the equality of rights and opportunities for men and women. In developing countries, however, the discourse for rich and poor is different, chiefly in what concerns policies for educational expansion. When the target population is poor, rural and colored, the policies follow a needs approach, of attending poorly the poor. It clearly appears in the World Bank documents. In this paper, a critical analysis of the early child education policies in developing countries is proposed, taking Latin America as a case study.

Contínuas mudanças econômicas e culturais refletem e provocam transformações sociais, causando modificações universais no funcionamento das famílias e na educação das crianças pequenas em todas as camadas sociais (Comissão Econômica para América Latina e Caribe - Cepal, 1998). Neste novo milênio, os contextos de desenvolvimento das famílias e das crianças são muito diferentes dos encontrados há três ou quatro décadas. $O$ crescente processo de industrialização, as guerras 
e conflitos que provocam migrações internas e externas, mudanças na concepção sobre a importância e influência dos primeiros anos de vida para o desenvolvimento posterior e a conquista de direitos da mulher e da criança são apenas alguns aspectos dessas transformações. Intensas mudanças, também, na estrutura familiar e no papel de cada um de seus membros têm ocorrido por conta da mobilização e crescimento da participação da mulher no mercado de trabalho (Arriagada, 1998). O número de mulheres com filhos com menos de seis anos de idade que passam diariamente longas horas no trabalho tem aumentado cada vez mais. Dados do National Institute of Child Health and Human Development - NICHD (1998) mostram que 62\% das mulheres americanas trabalhavam fora de casa em 1995. Todas essas questões têm contribuído para um grande aumento da demanda por educação/cuidado de crianças pequenas em contextos coletivos, seja pela quebra do apoio familiar e comunitário que contribuíam com os pais na educação de seus filhos, seja pelo desejo dos pais de fornecerem aos filhos oportunidades diversas daquelas encontradas na família.

Esse aumento da demanda é acompanhado por novas concepções sobre educação coletiva de crianças pequenas, influenciadas tanto pelas várias políticas que vêm sendo propostas e implementadas, buscando responder a esse processo social, como por avanços nas pesquisas e práticas sobre cuidado, desenvolvimento e educação infantil em creches e pré-escolas.

Do ponto de vista da pesquisa, nas últimas décadas, vários grupos, em todo o mundo, têm investigado aspectos relativos à educação de crianças pequenas fora do lar. Os avanços científicos estão produzindo bases de conhecimentos e knowhow necessários para subsidiar políticas educacionais e práticas de educação e cuidado infantil de qualidade, capazes de favorecer o desenvolvimento integral sadio das crianças. No Brasil, especificamente, a produção científica, na área, tem crescido muito nas últimas duas décadas', como mostra Rocha (1999).

Em relação aos avanços políticos e legais, também eles têm ocorrido nos mais diferentes países, acompanhados de uma crescente expansão de programas destinados às crianças pequenas, particularmente de educação infantil. No Brasil, por exemplo, a Constituição Federal de 1988 passou a definir a educação infantil

I. Nosso Centro de Investigações sobre o Desenvolvimento Humano e Educação Infantil Cindedi - tem contribuído para isso, com diferentes estudos: Amorim, Vitoria, RossettiFerreira, 2000; Rossetti-Ferreira, Amorim, Silva, 2000; Campos-de-Carvalho, Rossetti-Ferreira, 1993; Oliveira, Rossetti-Ferreira, 1993; Rossetti-Ferreira et al., 1998. 
como "um direito da criança, um dever do Estado e uma opção da família". Em 1990, o Estatuto da Criança e do Adolescente - ECA -, Lei n. 8.069/90, regulamentou artigos da Constituição Federal e explicitou mecanismos que possibilitam a exigência legal dos direitos da criança. Em 1996, foi promulgada a Lei de Diretrizes e Bases da Educação Nacional - LDB -, Lei Federal n. 9.394/96, que inclui efetivamente a educação infantil no sistema educacional brasileiro, compondo a primeira parte da educação básica. Os municípios devem, como decorrência, promover a integração das instituições de educação infantil aos seus sistemas de ensino, antes predominantemente atreladas à Assistência e Promoção Social (Guimarães, Pinto, no prelo). A partir da LDB, passou a haver uma preocupação específica com a formação do educador de educação infantil, tendo sido em princípio definida a formação no nível superior, embora seja aceita, no mínimo, a formação no magistério (ensino médio).

Esses avanços legais, a priori, podem assumir uma característica bastante generalizada e compartilhada por diferentes países, uma vez que se fundamentam principalmente no discurso da inclusão e integração social, sendo compreendidos como possibilidades de colocar em situação de igualdade diferentes populações. Entretanto, cabe-nos questionar se de fato esses avanços legais vêm se concretizando nos programas propostos para as crianças pequenas, com o mesmo significado, alcance e potencial em diferentes países. Interessa-nos principalmente compreender como esse processo tem-se configurado de formas diversas nos países desenvolvidos e naqueles em desenvolvimento, principalmente no que se refere às camadas mais pobres da população.

Mediante a análise crítica de dados macroeconômicos, sociais e do discurso oficial que norteia as políticas para a primeira infância nos países em desenvolvimento, verifica-se que as políticas propostas pelos governos e por agências multilaterais, como o Banco Mundial, têm concebido os programas de educação/cuidado infantil como uma forma de intervenção social para a superação das desigualdades. Recomendam-se, geralmente, diversos programas informais a serem implementados, como, por exemplo, o atendimento realizado por mães em seus próprios lares, o chamado programa mãe-crecheira. Esse programa concebido como "alternativo" quanto às opções de cuidado e educação de crianças, é também efetivado nos chamados países desenvolvidos, como, por exemplo, nos países nórdicos, que possuem grande tradição nesse tipo de atendimento. Em países em desenvolvimento, essa modalidade de atendimento preocupa quando se considera que ainda são baixos os índices de escolaridade da população e que existe uma tendência a orien- 
tar projetos com poucos investimentos na remuneração e treinamento/formação de pessoal. Essas práticas, que se situam no campo da assistência às camadas pobres da população, podem gerar um efeito contrário ao que aparentemente se propõem, incentivando a exploração da mão-de-obra feminina, a não-profissionalização do cuidado e da educação, assim como a criação de categorias diferenciadas de atendimento. Diferem em muito das propostas educacionais que visam à qualidade para o atendimento à infância que vêm sendo estabelecidas nos documentos publicados, por exemplo, pela European Commission Network on Childcare - ECNC (1990, 1992, 1996, 1996a) - e pela Organisation for Economic Co-operation and Development - OECD (2000).

Nos países da Comunidade Européia, as justificativas para essas políticas fundamentam-se em um discurso que objetiva tanto contribuir para o desenvolvimento da criança, dos seus direitos e acesso aos bens culturais como para o estabelecimento de políticas de eqüidade entre homens e mulheres (Rosemberg, 2000). Além disso, existe uma preocupação de atender a todas as crianças e famílias que queiram usufruir de programas de educação e cuidado para a infância, oferecendo uma ampla variedade de alternativas que respondam a necessidades diversas (ECNC, 1996a). Daí têm resultado medidas de flexibilização de horários de trabalho, licença maternidade e paternidade, diversificação nas formas de atendimento etc. Já nos países em desenvolvimento, embora pareçam fundamentar-se no direito da criança e da família, quando o alvo é a população pobre, negra e de zona rural, essas políticas se concentram em um discurso da necessidade, assentado no lema "atender pobremente a pobreza", que transparece de maneira clara nos documentos do Banco Mundial, maior agência internacional que orienta e subsidia programas para a infância.

A necessidade urgente de expansão do atendimento, principalmente às crianças das camadas pobres, consideradas pelas agências e governos como populações em situação de risco, vem se tornando a justificativa para a implantação de muitas políticas compensatórias que propõem programas descentralizados de baixo custo.

Neste artigo, propomo-nos a problematizar essas questões e trazer novos elementos e informações para uma reflexão crítica sobre elas, focalizando a América Latina.

\section{AMÉRICA LATINA E CARIBE COMO UM ESTUDO DE CASO}

Tendo em vista a necessidade de considerar a diversidade socioeconômica e cultural entre regiões e países no atendimento infantil, decidimos realizar uma aná- 
lise da América Latina e do Caribe, região que nos é mais familiar, embora ela também abrigue uma diversidade sociocultural, lingüística, econômica, política e geográfica que, continuamente, nos desafia.

Também foram incluídos, quando possível, dados de quatro diferentes países desenvolvidos de três continentes (Suécia/Europa, Japão/Ásia, EUA e Canadá/América do Norte), apenas como parâmetros comparativos.

O bloco latino-americano é formado por 3 I países com uma população total de aproximadamente 490,4 milhões (Fundo das Nações Unidas para a População, 1998). Para o nosso estudo nove países foram selecionados: Argentina, Brasil, Chile, Colômbia, Cuba, México, Peru, Uruguai e Venezuela. Os critérios para a seleção foram: importância política e econômica; engajamento dos países em algum tipo de política de educação e cuidado infantil e diversidade de componentes culturais apresentados pela amostra como um todo. Nesses países vivem cerca de $90 \%$ da população da América Latina. Os países do Caribe estão pouco representados: somente Cuba foi incluída nas investigações, por apresentar alguns aspectos contrastantes.

A informação necessária para realizar este estudo de caso foi, basicamente, obtida através de três fontes:

I. Revisão bibliográfica, realizada em quatro importantes bibliotecas², na internete em documentos recentes, produzidos em conferências ou fornecidos por especialistas.

2. Material enviado por 54 instituições dos oito países latino-americanos estudados, em resposta a solicitação nossa. As instituições contatadas foram selecionadas pelo Directory of Early Childhood Care and Education Organisations in Latin America and Caribbean (Unesco, 1996), incluindo as comissões nacionais da Unesco e de outras fundações internacionais, ministérios da educação, saúde e bem-estar social, institutos de pesquisa, universidades, organizações não governamentais e outros. $\bigcirc$ Brasil não foi incluído nesse serviço postal; os dados referentes ao país foram coletados por contato mais direto com as instituições e bibliotecas especializadas.

2. Da Fundação Carlos Chagas, em São Paulo, SP; do Instituto de Pesquisas Econômicas Ipea -, em Brasília, DF; do Instituto Interamericano del Niño, no Uruguai e do Centro de Investigação sobre Desenvolvimento Humano e Educação Infantil, em Ribeirão Preto, SP. 
3. Entrevistas com três especialistas de renome internacional: Dra. Fúlvia Rosemberg (pesquisadora da Fundação Carlos Chagas e professora da Universidade Católica de São Paulo - PUC-SP-) Dra. Maria Alice Setúbal (ex-representante para a área educacional do Fundo da Nações Unidas para a Infância - Unicef - na América Latina) e Dr. Robert Myers (The Consultative Group on Early Childhood Care and Development, and the High Scope Education Research Foundation, USA).

Os dados obtidos a respeito de cada país são bastante escassos e por vezes imprecisos. De forma geral, não foi possível obter uma avaliação homogênea de todos os países e, algumas vezes, a possibilidade de fazer comparações bem fundamentadas das avaliações ficou prejudicada por isso.

\section{MODELO DE ANÁLISE DAS POLÍTICAS E PROGRAMAS}

A complexidade do tema e das informações obtidas requer uma abordagem ampla e transdisciplinar. Ela comporta tanto a análise de dados macroeconômicos e de políticas advindas de agências internacionais como a consideração da peculiar comunicação intersubjetiva e características afetivas e emocionais da criança pequena (Braten, 1998). Faz-se necessária a utilização de um referencial que considere os diferentes aspectos e dimensões dos programas e das políticas de educação infantil. A partir de um estudo de caso realizado em 29 países de diferentes regiões do mundo, Cochran (1993) fornece um esquema interessante e apropriado para a identificação dos diversos fatores que conjuntamente produzem políticas e programas, assim como para a compreensão de por que diferentes causas produzem diversos tipos de programas e políticas.

Para desenvolver seu modelo, Cochran inspirou-se em Bronfenbrenner ( 1977). Este postula que o desenvolvimento deve ser compreendido em seu contexto, sendo o resultado de influências recíprocas e sinérgicas entre a pessoa em desenvolvimento e o ambiente em constante transformação, e concebe o ambiente ecológico topologicamente constituído como um arranjo de estruturas aninhadas, cada uma contida na seguinte. As estruturas ambientais e os processos que ocorrem dentro delas e entre elas devem ser vistos como interdependentes e analisados como sistemas, que são assim definidos:

Microssistema: ambiente imediato que contém a pessoa em desenvolvimento, tal como a creche, a escola, o lar, e os ambientes nos quais a pessoa se engaja em interações face a face. 
Mesossistema: inter-relações de dois ou mais ambientes nos quais a pessoa em desenvolvimento participa ativamente.

Exossistema: ambiente nos quais a pessoa não se encontra diretamente. Uma investigação desse sistema deve considerar o impacto das regiões mais remotas sobre os ambientes imediatos onde a pessoa está inserida. Este sistema inclui as instituições maiores da sociedade [...] dentre outros: o mundo do trabalho, a vizinhança, a relação entre serviço de saúde e bem-estar, agências governamentais (locais, estaduais e nacionais), a distribuição de bens e serviços, redes sociais informais e a expansão da rede de ensino.

Macrossistema: padrões generalizados da cultura ou subcultura, tais como: sistemas econômicos, sociais, educacionais, legais e políticos, dos quais o micro, meso e exossistema são manifestações concretas. [Macrossistemas] são analisados como portadores de informações e ideologias que, tanto de maneira explícita como implícita, dotam de significado e motivação as agências governamentais, redes sociais, papéis, atividades e suas inter-relações. (1977, p. 515, tradução nossa)

O estudo de Cochran constitui importante contribuição para analisar principalmente o impacto das dimensões do macrossistema sobre as políticas e programas. $\bigcirc$ autor propõe um esquema que ultrapassa a mera identificação de fatores causais, estimulando a análise da associação entre eles, as influências mediadoras da ordem do macrossistema e as tendências atuais em políticas de educação/cuidado para a infância. Esse esquema está configurado como uma ferramenta de análise com diversos componentes que interagem entre si, produzindo diferentes combinações e formas de atendimento. Para o autor a busca de um número de causas e mediadores possíveis não é infinita, visto que um certo grupo de fatores e influências é suficiente para compreender a razão pela qual as políticas e programas para a infância em um país se configuram de uma determinada maneira. A figura I apresenta o modelo desenvolvido por Cochran, com pequenas modificações introduzidas pelas autoras.

Como se pode verificar, para Cochran, o desenvolvimento de políticas e programas de um país é o resultado de uma combinação de fatores demográficos, econômicos, culturais e sociais, referidos pelo autor como "fatores causais". Fatores causais semelhantes podem produzir diferentes políticas e programas devido a "influências mediadoras" que atuam como filtros, "isolando alternativas de políticas e programas que são incompatíveis com elas" (Cochran, 1993, p. 629, tradução nossa). Dentre essas influências destacam-se: valores culturais, crenças e normas expressas pela família e religião, ideologias sociopolíticas, modelos de bem-estar, riqueza nacional e outros. Cochran aponta ainda que, embora as influências mediadoras 


\section{FIGURA I}

\section{ESQUEMA DE COCHRAN PARA ANÁLISE DE POLÍTICAS} E PROGRAMAS PARA A INFÂNCIA

\section{Fatores Causais}

Urbanização e Industrialização

Perda da estrutura familiar/ papel

tradicional

Mudança de papel da mulher

Mudanças nas taxas de natalidade

Mudanças políticas ou conflitos

Escassez ou excesso de mão-de-obra

Imigração/ migração

Pobreza ou declínio da qualidade de vida

Preparação inadequada para a escola

Falta de infra-estrutura de serviços

\section{Tendências em políticas e programas}

Provisão....... Não oferta

Criança..........Pais/comunidade como alvo

Quantidade........ Qualidade

Bebês.......Crianças pré-escolares

Financiamento público.......Privado

Regulamentado...... Não regulamentado

Institucional........Domiciliar

Formação inicial......... Em serviço

Currículo educacional ........... Custodial

Foco no desenvolvimento..........Escolarização

Abordagem pedagógica

Conteúdo cultural

Relação creche-família

\footnotetext{
Valores culturais, crenças e normas

(família e religião)

Ideologias sociopolíticas e econômicas

Políticas públicas de bem-estar

Riqueza nacional (Renda per capita GNP)

Variação intra-social

Intensidade e ritmo de urbanização

Políticas específicas para a família

Unidade ou multiplicidade institucional
} 
de caráter macro constituam norteadores fundamentais para a configuração de programas e políticas, um aspecto extremamente importante diz respeito à forma como cada cultura e indivíduo interpreta e atribui significado aos fatores causais. Essas interpretações e significações ampliam as possibilidades e operam também como mediadores e canalizadores de políticas e programas.

Ao realizar a análise conjunta dos 29 países, Cochran identifica ênfases nas políticas que podem variar de um a outro extremo, como mostra a figura I, no quadro "Tendências em políticas e programas".

Nosso enfoque, neste artigo, prioriza o macrossistema tal como abordado no modelo de Cochran, buscando principalmente discutir a relação entre alguns fatores e influências mediadoras na produção de discursos que permeiam a definição e elaboração de políticas e programas de educação/cuidado infantil na América Latina.

\section{PRESENÇA E DISCURSO DO BANCO MUNDIAL COMO MEDIADOR}

O Banco Mundial é o agente central de gerenciamento de relações de crédito internacional e encontra-se bastante presente no financiamento de diversos programas de países da América Latina. Ele define e financia, no mundo, programas associados a investimentos do Fundo Monetário Internacional - FMI.

Nos anos 70, o Banco Mundial começou a trabalhar com uma diversificação dos créditos. Um deles foi para o setor social e, de 1977 em diante, a educação fundamental foi incluída como um componente básico para erradicar a pobreza. Nos anos 80, as políticas educacionais do Banco Mundial estabeleceram, entre outras metas, a universalização da educação fundamental, a flexibilidade da oferta, assim como a descentralização administrativa e financeira e a melhoria de sua qualidade (Soares, 1999). Em 1990, a ajuda financeira do Banco Mundial para a educação em países em desenvolvimento contabilizou, no mundo, 62\% do total investido pelas agências internacionais multilaterais (Lauglo, 1996). De 1994 a 1995, o banco investiu e emprestou 250 bilhões de dólares em 3.660 projetos (Soares, 1999).

A partir dos anos 90, o Banco Mundial definiu a educação básica como alvo principal, incluindo a educação infantil (Young, 1996; Banco Mundial, 1996), e foram propostas políticas educacionais homogêneas para todos os países da América Latina. Estas, por sua vez, têm tido profunda influência na formulação de políticas e estratégias de educação pública e na definição do modelo de desenvolvimento a ser seguido pelos governos locais. $\bigcirc$ banco apresenta suas propostas partindo de justi- 
ficativas econômicas e científicas, denominando-as "programas de desenvolvimento infantil". Propõe a educação e o cuidado infantil como um meio de promover a saúde e o desenvolvimento da criança, associado a eles outros programas, como nutrição e saúde da mulher. Além disso, a educação e o cuidado infantil são vistos como um recurso para o desenvolvimento não apenas da criança, mas também de toda a sociedade (Young, 1996). Nesse sentido, estão sendo postas em prática diversas políticas para famílias com crianças pequenas como formas de intervenção social para prevenir o fracasso escolar e quebrar o ciclo de pobreza, evitando, assim, desajustes posteriores.

As justificativas econômicas para o investimento na primeira infância pautamse na premissa de que é necessário investir desde cedo no desenvolvimento das crianças para que, na vida adulta, elas possam inserir-se no mercado de trabalho e produzir satisfatoriamente, o que reduz gastos futuros com educação e saúde. A justificativa científica para a implantação de programas do que passou a ser denominado desenvolvimento infantil parte de pesquisas baseadas nas neurociências, que sugerem que o potencial de uma criança é definido pelas suas experiências durante os primeiros anos de vida. $\bigcirc$ Banco Mundial apropriou-se do discurso de que investir no desenvolvimento da criança pequena abre "janelas de oportunidade" para o indivíduo posteriormente. Se esse período não for aproveitado, as possibilidades de desenvolvimento ficarão prejudicadas. Ressuscita-se assim a idéia de períodos sensíveis, discutida e abandonada há algumas décadas. Penn (2000*) critica as fontes usadas pelo banco para apoiar seu discurso, afirmando que as justificativas são afirmações pautadas em dados exclusivos dos EUA, que deixam de lado outros países desenvolvidos como os da União Européia, o que compromete a fidedignidade dos dados. Segundo Penn, as pesquisas são contraditórias e seus dados indevidamente generalizados, visto que foram obtidos na América do Norte e dizem respeito àquela realidade. Para a autora, essas pesquisas focalizam a criança individualmente, como um ser passivo e totalmente dependente do adulto, além de conceber a família nuclear como modelo e excluir outras formas de estruturação familiar. Tais pesquisas, na realidade, apontam para uma desejável concepção de criança e sociedade pautada no modelo norte-americano de desenvolvimento.

Cabe lembrar que os investimentos, como apontado por Lauglo (1996) e Miranda (1997), impõem severas condições e diretivas para os países e órgãos que requerem e recebem seus empréstimos, atrelando os créditos a ajustes macroeco-

\footnotetext{
* O artigo, traduzido para o português, está publicado, nas p. 7-24, desta edição (N. da E.).
} 
nômicos que causam, freqüentemente, aumento nas tensões sociais e interferem nas políticas de distribuição de renda, o que perpetua a exclusão social. Trata-se da reatualização do "lidar pobremente com a pobreza", como classificado por Franco ( 1989) e Rosemberg (2000) em suas críticas às políticas educacionais do Banco Mundial. Este discurso exige uma análise meticulosa daquilo que está sendo proposto na forma de "programas alternativos" a serem implementados em países em desenvolvimento, tal como explicitam as citações a seguir:

Programas informais que empregam mães, supervisores e moradias particulares são bem mais baratos do que programas formais. Com uma boa supervisão eles podem atingir um serviço de boa qualidade. (Wolff, Schiefelbein, Valenzuela, 1994, tradução nossa)

O uso de moradias particulares com uma infra-estrutura mínima pode ajudar a reduzir custos. Qualquer lugar seguro, com instalações sanitárias mínimas e uma cozinha, é suficiente. A alimentação é o custo maior do programa, cerca de $40 \%$ do total [...]. Sempre é possível adquirir alimentos através do governo ou de doações internacionais [...]. O custo da assistência primária em moradias particulares com o emprego das mães é estimado em cinco vezes mais barato do que o custo educacional em centros formais. (Young, 1996, tradução nossa)

Um primeiro interesse suscitado por tais orientações refere-se à compreensão do impacto dessas políticas para a promoção efetiva de melhoria das condições de vida e educacionais da população, em particular, da América Latina. De fato, as condições econômicas desses países sempre são apontadas como restrições para o investimento maciço em programas educativos, e políticas "alternativas" acabam sendo bem vistas nessas situações. Um outro, diz respeito ao alcance e às conseqüências dessas propostas em relação às culturas e realidades específicas dos países que compõem esse bloco. Quanto ao primeiro aspecto, necessitamos caracterizar o contexto latino-americano e analisar alguns indicadores de cobertura do atendimento às crianças pequenas que ofereçam evidências de alguma melhoria. Quanto ao segundo aspecto, retornaremos ao assunto, discutindo de modo mais aprofundado os documentos estudados e as ditas políticas "alternativas", focalizando a discussão na proposta denominada "mãe-crecheira" ou "creche domiciliar".

\section{O DISCURSO DOS NÚMEROS: O CONTEXTO LATINO-AMERICANO}

Para compreender o contexto latino-americano tomaremos alguns elementos do macrossistema retirados do Índice de Desenvolvimento Humano publicado 
pela Organização das Nações Unidas - ONU - desde 1990. Eles se referem a vários indicadores para fazer uma avaliação da qualidade de vida numa amostra de 174 países ao redor do mundo, apontando melhorias e retrocessos ao longo dos anos em países específicos.

Os parâmetros mais discriminativos do Índice de Desenvolvimento Humano - IDH - para a América Latina e Caribe estão apresentados na tabela I, de modo a proporcionar uma visão geral das condições de vida da população da região, em contraste com a da América do Norte, Japão e Suécia. $\mathrm{O}$ IDH baseia-se em três indicadores principais: longevidade, medida pela expectativa de vida; nível educacional, medido pela combinação do número de adultos alfabetizados e matrícula nos três níveis de escolaridade; padrão de vida, medido pelo Produto Interno Bruto PIB - real per capita. Para a construção do IDH foram estabelecidos alguns valores fixos mínimos e máximos para cada indicador: expectativa de vida: 25 e 85 anos, adultos alfabetizados: 0 a 100\% e PIB real per capita - PPC: 100 e 40 mil dólares.

$\mathrm{O}$ IDH calculado como uma média aritmética simples dos três índices componentes varia de 0 a I e pretende mostrar a distância de cada país em relação ao valor máximo I, assim como permitir comparações entre países. A análise da tabela mostra que a população de 490,4 milhões da América Latina é distribuída de maneira desigual entre os países. $\bigcirc$ Brasil, o único país de língua portuguesa, abrange um terço, enquanto o México, a Colômbia e a Argentina juntos perfazem o outro terço.

Os dados sobre a população urbana indicam que mais de $70 \%$ e, muitas vezes, mais de $80 \%$ da população de cada país vive em zonas urbanas. Nas últimas décadas (1975-1997), em toda a América Latina e no Caribe, tem ocorrido uma grande migração para os centros urbanos. Esse movimento segue a tendência mundial que já vinha sendo observada nos países usados como comparação.

Os países da América Latina e Caribe apresentam um índice de 0,756 IDH (0-I). A posição desses países no IDH ( I-174) é baixa, quando comparada aos países desenvolvidos, o que indica a baixa qualidade de vida de uma grande parte da população. $\bigcirc$ Chile $\left(34^{\circ}\right)$ apresenta a melhor posição, enquanto que o Brasil $\left(79^{\circ}\right)$ e o Peru $\left(80^{\circ}\right)$ apresentam as piores posições da amostra.

O PIB per capita geralmente é muito baixo; a maior parte dos países tem, no máximo, um terço do PIB dos países desenvolvidos. Cuba tem o PIB mais baixo, mas seu IDH é médio, por outro lado, apresenta baixas taxas de mortalidade. Esse contraste revela, provavelmente, a alta prioridade que as políticas de saúde têm tido em Cuba. 
TABELA I

ALGUNS INDICADORES DO ÍNDICE DO DESENVOLVIMENTO HUMANO NA AMÉRICA LATINA E CARIBE E NA AMÉRICA DO NORTE, JAPÃO E SUÉCIA

\begin{tabular}{l|r|r|r|r|r|r}
\hline \multirow{2}{*}{ País } & População & \multicolumn{2}{|c|}{ População Urbana (\%) } & IDH (0-I)*e Rank & PIB per capita & PIB per \\
& (milhões) & 1975 & 1997 & do IDH (I74) & (PPS \$ ) & $\begin{array}{r}\text { capita 20\% } \\
\text { ricos/pobres* }\end{array}$ \\
\hline Chile & 14.6 & 78.4 & 84.2 & $0.844\left(34^{\circ}\right)$ & 12,730 & 17.4 \\
Argentina & 35.7 & 80.7 & 88.6 & $0.827\left(39^{\circ}\right)$ & 10,300 & - \\
Uruguai & 3.3 & 83.1 & 90.7 & $0.826\left(40^{\circ}\right)$ & 9,200 & - \\
Venezuela & 22.8 & 75.8 & 86.5 & $0.792\left(48^{\circ}\right)$ & 8,860 & 16.2 \\
México & 94.3 & 62.8 & 73.8 & $0.786\left(50^{\circ}\right)$ & 8,370 & 13.5 \\
Colômbia & 40.0 & 60.7 & 73.6 & $0.768\left(57^{\circ}\right)$ & 6,810 & 15.5 \\
Cuba & 11.1 & 64.2 & 76.7 & $0.765\left(58^{\circ}\right)$ & 3,100 & - \\
Brasil & 163.7 & 61.2 & 79.6 & $0.739\left(79^{\circ}\right)$ & 6,480 & 32.1 \\
Peru & 24.4 & 61.5 & 71.6 & $0.739\left(80^{\circ}\right)$ & 4,680 & 10.3 \\
América Latina e Caribe & 490.4 & 61.2 & 74.2 & 0.756 & 6,868 & - \\
Canadá & 30.3 & 75.6 & 76.8 & $0.932\left(1^{\circ}\right)$ & 22,480 & 7.1 \\
USA & 271.8 & 73.7 & 76.6 & $0.927\left(3^{\circ}\right)$ & 29,010 & 8.9 \\
Japão & 126.0 & 75.7 & 78.4 & $0.924\left(4^{\circ}\right)$ & 24,070 & 4.3 \\
Suécia & 8.9 & 82.7 & 83.7 & $0.923\left(6^{\circ}\right)$ & 19,790 & 4.6 \\
\hline & & & & &
\end{tabular}

Fonte: PNUD, 1999. Baseado, predominantemente, em dados de 1997.

* IDH: medidas combinadas de longevidade, nível educacional e qualidade de vida.

*** As variações foram calculadas considerando-se o período de 1980 a 1994. 
Os dados da tabela I, representando o PIB per capita dos 20\% mais ricos em comparação com os $20 \%$ mais pobres indicam a heterogeneidade das condições de vida encontradas em cada país. Infelizmente, o Brasil, que tem a maior população do bloco, é o campeão mundial em termos de desigualdade de distribuição. Os 20\% mais ricos no país, isto é, uma população de 33 milhões de pessoas, têm um PIB per capita 32 vezes maior que os 20\% mais pobres, enquanto na Suécia este índice é de 4.6, no Japão, 4.3, nos EUA, 8.9 e no Canadá, 7. I.

significado desses dados permite redimensionar a questão acerca das diferenças entre países desenvolvidos e em desenvolvimento, merecendo uma análise mais minuciosa. Estamos falando de "países em desenvolvimento" ou estamos falando de grandes grupos populacionais diversos convivendo num mesmo país? Os 20\% mais ricos vivem em condições similares aos "países de primeiro mundo", com amplo acesso a serviços e produtos modernos. Esse grupo abrange uma população equivalente à do Canadá e quase quatro vezes maior que a da Suécia. Por outro lado, os $20 \%$ mais pobres vivem em condições muito precárias, semelhantes às condições dos países "subdesenvolvidos", com os piores IDH, como Serra Leoa, um pequeno país africano que tem a pior posição no $\mathrm{IDH}\left(174^{\circ}\right)$. Esses indicadores caracterizam as condições bastante desiguais e cruéis nas quais vive a população, visto que grande parte encontra-se à periferia da modernização e do desenvolvimento. Nesse sentido, as políticas assentadas no discurso do Banco Mundial teriam o mesmo efeito para esses dois grandes blocos sociais? Não estariam essas políticas contribuindo ainda mais para a configuração de duas categorias de atendimento, uma destinada às camadas mais altas e outra, aos excluídos?

Quanto à magnitude da pobreza e da indigência na América Latina, a Cepal ( 1998 ) afirma que mais de 35\% e 15\% das famílias da América Latina vivem respectivamente abaixo do nível de pobreza e de indigência. Estes indicadores são ainda piores entre lares rurais, nos quais $31 \%$ das famílias vivem abaixo do nível de indigência e mais de 54\% vivem abaixo da linha de pobreza. A Cepal (1998) classifica como indigentes os lares nos quais a renda per capita não é suficiente para comprar comida para suprir exigências calóricas básicas, acarretando, portanto, sérios riscos de desnutrição; a linha de pobreza é definida como duas vezes a linha de indigência. Durante as duas últimas décadas, os dois índices mantiveram-se razoavelmente estáveis na América Latina como um todo, embora tenham sido observadas, entre os países, tendências opostas. $\bigcirc$ Brasil e o Chile apresentaram alguns pequenos avanços, enquanto na Colômbia e na Venezuela o nível de pobreza e indigência aumentou tanto na zona urbana quanto na rural. 
Alguns poucos avanços homogêneos podem ser observados, como aqueles relacionados à taxa de mortalidade infantil nos países pobres. Observa-se que essas taxas têm caído nos últimos anos, embora essa queda tenha sido mais acentuada nos países desenvolvidos. As quedas observadas resultam dos vários avanços ocorridos nas ciências médicas e biológicas, nas políticas de saúde, educacionais e sanitárias. Cuba apresenta a menor taxa comparada aos países da América Latina e do Caribe (sete crianças por mil nascimentos), aproximando-se das taxas dos EUA. Peru e Brasil apresentam altas taxas, $44 \%$ e $37 \%$ respectivamente, apesar de se registrar uma queda média de $61 \%$ nos últimos 27 anos.

A taxa de fertilidade na América Latina e no Caribe também baixou de 4,7 para 2,7 crianças por mulher na idade reprodutiva, de 1975 a 1997 (Programa das Nações Unidas para o Desenvolvimento - PNUD, 1999), seguindo a tendência observada anteriormente em países do primeiro mundo. De fato, essa queda não é homogênea, pois uma associação entre desigualdade e o número de crianças por família foi observada em muitos dos países estudados. No entanto, apesar da redução, observa-se que na América Latina, de modo geral, a tendência de as famílias pobres terem mais de dois filhos é maior que nas famílias mais ricas. Mulheres com alta qualificação profissional tendem a ter menos filhos. Desse modo, mulheres com seis anos de escolaridade têm, em média, 0,7\% mais filhos do que aquelas que completam 13 anos de escolaridade (Cepal, 1998). O Banco Interamericano de Desenvolvimento - BID ( 1998) levantou algumas hipóteses para explicar tais diferenças; elas podem estar relacionadas ao fato de que a educação lhes proporciona um número maior de alternativas no dia-a-dia, modifica suas preferências pessoais e aumenta a possibilidade de obterem maior renda, tornando sua inserção no mercado de trabalho mais atrativa.

Em vários países, a participação da mulher no mercado de trabalho é mais baixa que a do homem, como pode ser observado na tabela 2. A diferença média é de 37\% em toda a América Latina, enquanto nos países industrializados a discrepância é menor que 20\%. Além disso, muitas mulheres trabalham no setor informal, em que as condições de trabalho são mais precárias e a remuneração é mais baixa. A marcante presença da mulher no mercado informal tem sido atribuída às expectativas tradicionais que induzem a mulher a procurar trabalhos que ofereçam maior flexibilidade, de modo a estarem mais disponíveis para propiciar cuidado e sustento às crianças, pessoas doentes e idosas (Arriagada, 1998). Para as mulheres pobres e com baixo nível educacional torna-se mais difícil manter horários rígidos de trabalho, pois, quase sempre, não têm meios de organizar uma rede de apoio 
que lhes possibilite contar com pessoas com quem possam dividir suas tarefas domésticas e parentais. Aquelas que têm melhor escolaridade podem se candidatar a salários melhores e, portanto, estão mais aptas a pagarem por esse apoio.

Ainda em relação à questão de gênero, observa-se certa segregação no campo profissional. Apesar da recessão, que tem causado aumento nas taxas de desemprego na América Latina na última década (BID, 2000), os postos de trabalho disponíveis ainda apresentam possibilidades maiores para os homens que para as mulheres, como visto na tabela 2.

Arriagada (1998) afirma que o planejamento de políticas públicas deveria levar em conta as mudanças que estão acontecendo na instituição familiar em toda a América Latina. Entre essas, ela se refere à redução no tamanho da unidade familiar; à diminuição ou ao adiamento de uniões conjugais formais; ao aumento da maternidade precoce, principalmente nas camadas sociais mais baixas; ao aumento das uniões consensuais, dos rompimentos matrimoniais, do número de famílias monoparentais e também de outras configurações familiares. De acordo com os dados da Cepal ( 1994), os lares dirigidos por mulheres já haviam atingido I 6,8\% no México e 25,8\% no Uruguai, que apresentou a maior taxa deles. Esses lares, freqüentemente, possuem renda abaixo do nível de indigência.

Em relação ao nível educacional como um todo, e particularmente em relação à origem socioeconômica, os dados continuam a confirmar uma situação bastante desigual, que pode ser verificada na tabela 3.

Verifica-se que o nível de escolaridade da população adulta latino-americana varia muito de país para país e em zonas rurais e urbanas.

O nível médio de escolaridade varia de dez anos, na zona urbana do Chile e na Grande Buenos Aires, a três anos, entre a população rural brasileira. $\bigcirc$ nível educacional diminui à medida que baixa o nível de renda da população. $\bigcirc$ nível educacional mais baixo é encontrado entre os $25 \%$ mais pobres do Brasil, os quais atingem 3,9 e I,7 anos de escolaridade nas zonas urbana e rural, respectivamente. Isto compreende uma população de cerca de 40 milhões de pessoas que tiveram precário acesso à escola ou que foram excluídas dela muito cedo.

Os índices aqui apresentados são bastante claros e, apesar de alguns avanços, como em relação à taxa de mortalidade infantil e fertilidade, eles apontam para uma situação ainda bastante insatisfatória quando comparada aos países desenvolvidos. Isso significa que muitos esforços devem ainda ser feitos para a melhoria do nível educacional, do acesso da população aos diferentes níveis do ensino, para uma distribuição mais equânime de renda e melhoria das condições de vida como um 
TABELA 2

PARTICIPAÇÃO DA MULHER EM ATIVIDADE ECONÔMICA

FORA DO LAR (ZONA URBANA \%)

\begin{tabular}{|c|c|c|c|c|c|c|}
\hline \multirow[t]{2}{*}{ País } & \multirow[t]{2}{*}{ Ano } & \multicolumn{2}{|c|}{ Homens* } & \multicolumn{3}{|c|}{ Mulheres* } \\
\hline & & \begin{tabular}{|c|} 
Participação na \\
atividade \\
econômica
\end{tabular} & $\begin{array}{l}\text { Empregos } \\
\text { domésticos }\end{array}$ & \begin{tabular}{|c|} 
Participação na \\
atividade \\
econômica
\end{tabular} & \begin{tabular}{|l|} 
Empregos \\
domésticos
\end{tabular} & $\begin{array}{l}\text { Proporção do } \\
\text { sal. do homem }\end{array}$ \\
\hline $\begin{array}{l}\text { Argentina (Grande } \\
\text { Buenos Aires) }\end{array}$ & 1997 & 76 & 0.4 & 45 & 12.7 & 79 \\
\hline Brasil & 1996 & 80 & 0.8 & 50 & 19.7 & 68 \\
\hline Chile & 1996 & 74 & 0.2 & 39 & 16.3 & 73 \\
\hline Colômbia & 1997 & 78 & 0.2 & 50 & 10.4 & 77 \\
\hline México & 1996 & 80 & 0.9 & 41 & 8.3 & 73 \\
\hline Uruguai & 1997 & 73 & 0.2 & 47 & 16.9 & 67 \\
\hline Venezuela & 1997 & 83 & 1.5 & 46 & 9.7 & 83 \\
\hline
\end{tabular}

Fonte: Cepal - Comissão Econômica para América Latina e Caribe, 1998.

* Trabalhadores Urbanos, 25 a 59 anos de idade, trabalhando 35 horas por semana ou mais.

TABELA 3

MÉDIA DE ANOS DE ESCOLARIZAÇÃO POR RENDA

FAMILIAR NA AMÉRICA LATINA

\begin{tabular}{l|c|c|c|c|c|c|c|c|c|c|c}
\hline País & \multirow{2}{*}{ Anos } & \multicolumn{5}{|c|}{ Zona Urbana } & \multicolumn{5}{c}{ Zona Rural } \\
\cline { 3 - 10 } & & Total & Q1 & Q2 & Q3 & Q4 & Total & Q1 & Q2 & Q3 & Q4 \\
\hline Argentina (Grande & & & & & & & & & & & \\
Buenos Aires) & 1997 & 10.0 & 7.4 & 8.7 & 10.4 & 13.2 & - & - & - & - & - \\
Brasil & 1996 & 6.6 & 3.9 & 5.4 & 7.1 & 10.3 & 3.0 & 1.7 & 2.5 & 3.2 & 5.4 \\
Colômbia & 1997 & 8.6 & 6.1 & 7.3 & 9.0 & 11.9 & 4.5 & 3.3 & 4.0 & 4.3 & 6.5 \\
Chile & 1996 & 10.4 & 8.2 & 9.5 & 10.8 & 13.1 & 6.3 & 5.5 & 6.1 & 6.2 & 7.7 \\
Uruguai & 1997 & 8.9 & 6.9 & 8.2 & 9.5 & 11.9 & - & - & - & - & - \\
Venezuela & 1997 & 8.4 & 6.3 & 7.5 & 8.5 & 10.9 & - & - & - & - & - \\
\hline
\end{tabular}

Fonte: Cepal - Comissão Econômica para América Latina e Caribe, 1998.

Baseado em levantamentos nos lares classificados pela renda por quartil Q1, Q2, Q3, Q4.

População de 25 a 59 anos de idade. 
todo. Mais do que isso, há uma desigualdade interna nos países que é atravessada pela questão de gênero, condições econômicas e zona de moradia e também pela questão étnica. As mulheres, indígenas, negros e moradores de regiões rurais sofrem de modo mais intenso os efeitos da desigualdade social.

São essas diferenças e esses dados que vêm sendo utilizados para justificar as políticas públicas de assistência e educação para os países da América Latina, fundamentando o discurso do Banco Mundial.

Entretanto, são esses mesmos dados que indicam que essas políticas só tendem a reforçar a desigualdade já existente entre os diferentes estratos sociais. Por exemplo, no que se refere à questão de gênero, são propostas ações que incrementem a participação feminina no mercado de trabalho e, dentre elas, surge aquela que indica a possibilidade de criar mercado de trabalho para as mulheres de baixa renda mediante a institucionalização do cuidado e educação de crianças nos seus próprios lares. Diante de todos os índices de escolaridade dessas populações, e em especial da população feminina, pergunta-se sobre a possibilidade, dentro das reais perspectivas de promover alguma inclusão, seja das crianças, seja das próprias mulheres, com políticas dessa natureza. Um dado a mais para pensar as limitações da proposta: a Cepal (1998) considera as crianças de 0 a 5 anos de idade, que têm mães com escolaridade inferior a seis anos, em risco de aquisição de capital educacional para o seu desenvolvimento e aprendizado. De acordo com este indicador, entre um quarto e metade da população do Brasil, Colômbia e Venezuela encontram-se nessa grave situação.

Mas a questão sobre os países pobres não está apenas na necessidade de assegurar a igualdade de direito entre homens e mulheres, mas também de assegurar a igualdade de direitos em relação a etnia e camadas sociais (Rosemberg, 1999a). Esta autora realizou comparação do acesso à educação formal no que se refere à questão do gênero, verificando que a situação brasileira assemelha-se à dos países ricos em patamar inferior:

Observam-se oportunidades e barreiras equivalentes associadas à origem socioeconômica e ao pertencimento racial: mulheres e homens brancos, de bom nível de renda familiar dispõem de boas e semelhantes oportunidades educacionais. [...] mulheres e homens não brancos e com pequena renda familiar dispõem, igualmente, de péssimas condições educacionais. (Rosemberg, 1999a, p. 8).

Essa realidade estratifica e hierarquiza a população, refletindo assim uma política também hierarquizada, com discursos e oportunidades diferentes a depender 
do segmento social. Essa hierarquia não ocorre apenas numericamente, mas, sobretudo, reflete-se na diferença de qualidade dos serviços oferecidos aos vários segmentos sociais.

A disparidade dos índices aponta que, com certeza, políticas destinadas a países em desenvolvimento, mesmo que com a mesma orientação das destinadas a países desenvolvidos, terão resultados e efeitos diferentes em razão da realidade local.

\section{O DISCURSO DOS NÚMEROS: A COBERTURA DO ATENDIMENTO}

A importância atribuída à educação em todo o mundo fez com que a Conferência Mundial de Educação para Todos, realizada em Jomtien, na Tailândia, em 1990, declarasse os anos 90 como a Década da Educação. Os resultados do investimento social e econômico nesta área, em todos os países da América Latina e do Caribe, feitos também através de entidades como o Unicef e a Fundação Van Leer, além do Banco Mundial, já podem ser avaliados em melhorias observadas, nos anos recentes, nas taxas brutas de matrícula nos três níveis de escolaridade e nas taxas de analfabetismo de adultos, como mostrado pelos relatórios do IDH (PNUD, 1999). Também foi observado um aumento nas taxas brutas de matrícula nos programas de educação e cuidado infantil no mundo e, em particular, na América Latina durante a última década, conforme mostra recentemente Robert Myers (2000), ao avaliar os efeitos dos programas de cuidado e desenvolvimento infantil, formulados em decorrência da Conferência de Educação para Todos, como se pode constatar na tabela 4.

Para Myers não é possível comparar a taxa bruta de matrícula na pré-escola entre países, porque o ano-base e o ano mais recente para o qual os números são contados são diferentes, os programas incluídos no cálculo não são do mesmo tipo e os agrupamentos por idade nos dados relatados diferem drasticamente. Ele conclui que todos os países mostraram algum aumento, ao longo da década, no número de matrículas. Em alguns casos, esse aumento foi bem pequeno, como na Bolívia e na Guatemala (aumento de 3,2 \% e 6, I\%, respectivamente, entre 1990 e 1998). A variação tanto nos países como entre eles comparativamente é muito grande. Segundo o autor, muitos países atingem mais de 80\% para as idades de 5 anos em diante: México, Peru, Chile, Costa Rica Cuba e Uruguai. $\bigcirc$ número de matrículas para até 4 anos de idade permaneceu muito baixo na região, possivelmente por conta da concepção predominante de que a mãe é quem cuida da criança pequena, refletindo ênfase maior nos programas de preparação imediata para a escola. Pro- 
TABELA 4

PROPORÇÃO DA TAXA DE MATRÍCULA EM PROGRAMAS DE EDUCAÇÃO/DESENVOLVIMENTO INFANTIL*: AMÉRICA LATINA (\%)

\begin{tabular}{l|c|c|r}
\hline País & Idade (variação) & Matrícula por volta de 1990 & Matrícula por volta de 1998 \\
\hline Argentina a/ & - & 21.6 & - \\
Brasil b/ & $0-3$ & - & 7.4 \\
Brasil & $4-6$ & $35.4(91)$ & $45.6(96)$ \\
Colômbia & $5-6$ & - & $41.7(97)$ \\
Chile & $0-5$ & 20.9 & 30.3 \\
Cuba & $0-5$ & 29.1 & 98.0 \\
México & $3-5$ & 62.2 & 76.3 \\
Peru & $3-5$ & 52.3 & 60.9 \\
Uruguai & $3-5$ & - & $51.9(1996) / 63.2(1999)$ \\
Venezuela a/ & - & 20.8 & - \\
\hline
\end{tabular}

Fonte: Myers, 2000.

a/ Fonte: Unesco/Orealc, 1996. Os grupos são definidos apenas como pré-escolares, sem especificação de idade. b/ Fonte: IBGE-PPV/ 96, 1996.

* Meio período e integral.

vavelmente, isto também se traduz no padrão de demanda da população, apesar de os próprios relatórios não examinarem os dados relacionados a inserção no mercado de trabalho e atitudes dos membros familiares.

Entretanto, assim como os indicadores da América Latina como um todo, também os dados sobre a extensão da educação infantil demonstram que a melhoria nos índices deve ser vista com cautela quanto à sua extensão. A política educacional que visa ao rápido crescimento dos índices encobre, em vários casos, nuanças e, em certa medida, privilegia o resultado quantitativo em detrimento da qualidade da educação. Os dados sobre expansão da educação infantil por nível de renda, analisados por Myers, apontam também para um viés socioeconômico e urbano, pois a população urbana e mais rica apresenta taxas de matrícula mais elevadas nos programas de cuidado e desenvolvimento infantil. Apesar de ter sido observado um nítido aumento entre 1990 e 1996, o viés em direção à maior cobertura nos quintis de maior renda ainda permanece, e o menor aumento ocorreu nas camadas mais baixas.

No Brasil, a Fundação Instituto Brasileiro de Geografia e Estatística - FIBGE (1997) - coletou algumas informações relativas ao uso de creches e pré-escolas 
pela população conforme a renda familiar e o nível de escolaridade materna numa investigação dos padrões de vida, baseada em amostra de lares das regiões Nordeste e Sudeste, que cobrem cerca de $70 \%$ da população brasileira. A figura 2 aponta claramente para uma correlação positiva entre a escolaridade infantil e as duas variáveis: renda familiar e escolaridade materna nos dois grupos etários considerados: crianças de 0 a 3 anos e crianças de 4 a 6 anos de idade.

Apenas 35\% das crianças de 4 a 6 anos de 20\% dos lares mais pobres estão em pré-escolas. Entre os $20 \%$ mais ricos, a porcentagem aumenta para $84 \%$. Para as crianças de 0 a 3 anos, esses índices são 2\% para os mais pobres e 35\% para os mais ricos. As diferenças aumentam quando o nível de escolaridade materna é levado em conta. Quase todas as crianças cujas mães têm grau universitário freqüentam pré-escolas e a maioria delas já está matriculada desde os primeiros anos de vida. Em contraste, menos de $50 \%$ das crianças, cuja as mães têm escolaridade inferior a quatro anos, freqüentam pré-escolas, e a porcentagem cai para $3 \%$ quando a criança tem menos de 3 anos de idade.

Rosemberg (1999 e 1999a) argumenta que a expansão da educação infantil no Brasil não pode ser analisada somente sob a ótica do aumento da oferta de vagas, mas também das diferenciações internas decorrentes dessa expansão. A autora adverte que os notáveis índices de crescimento para os diferentes segmentos populacionais, independentemente do nível de renda, localização urbana ou rural, raça e sexo, podem erroneamente falar em favor de uma democratização do ensino. Cita o programa de expansão realizado no Brasil, na década de 70, no qual as pré-escolas, destinadas às crianças de camadas médias, tiveram a garantia de profissionais com formação em magistério, enquanto as creches, majoritária e historicamente destinadas às camadas pobres, estiveram caracterizadas pela nãoprofissionalização dos educadores e pela implementação de políticas a baixo custo. Além disso, esse modelo econômico de expansão ocorre de modo muito mais localizado, afetando principalmente a região Nordeste do país e as populações negras e pardas e moradoras de zona rural. Dados como esses apontam que os índices de cobertura da educação infantil não têm o mesmo significado nem mesmo nos diferentes estados brasileiros, caracterizando-se muito mais por uma demografização do atendimento do que democratização. A educação infantil tem se tornado a primeira etapa no processo de exclusão social.

A exemplo de demais países da América Latina, a expansão no Brasil tem ocorrido a partir da implantação de políticas com uma cobertura seletiva, priorizando camadas da população, nível de escolaridade e raça. 
FIGURA 2

ESCOLARIDADE DA CRIANÇA POR RENDA FAMILIAR E ANOS

DE ESCOLARIDADE DA MÃE NO BRASIL, POR GRUPO ETÁRIO
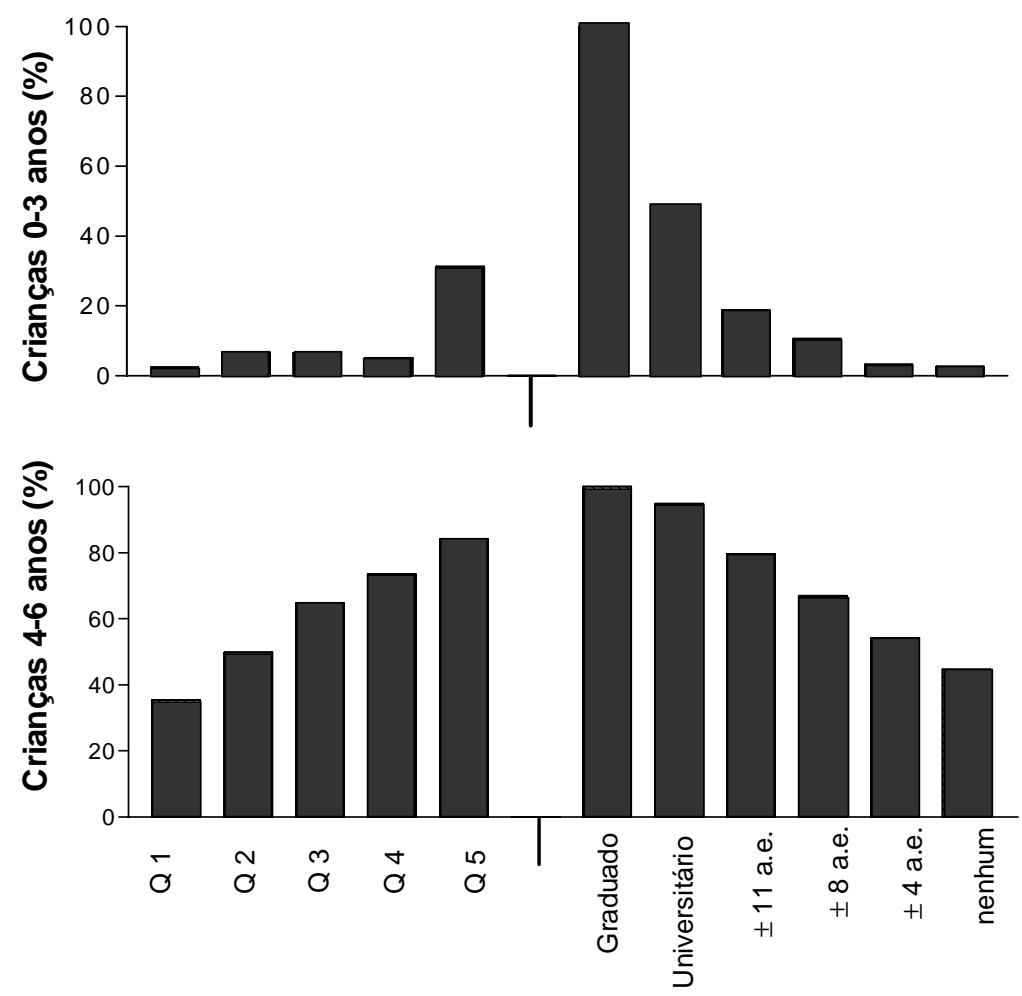

Renda Familiar (Quintil)

Nível de Escolaridade da Mãe (anos de escolaridade) 
Diferentemente, na Comunidade Européia a expansão parece vir atrelada à igualdade de oportunidades entre homens e mulheres e de acesso à educação/ cuidado de qualidade para a criança pequena.

\section{UMA AVALIAÇÃO CRÍTICA DAS POLÍTICAS E PROGRAMAS}

As diferenças entre as concepções presentes nos países desenvolvidos e em desenvolvimento devem ser pensadas com base nos discursos que fundamentam essas concepções. Jonsson propõe duas perspectivas que se contrapõem na base das políticas públicas para a infância, denominadas por ele "perspectiva de necessidade" e "perspectiva de direitos":

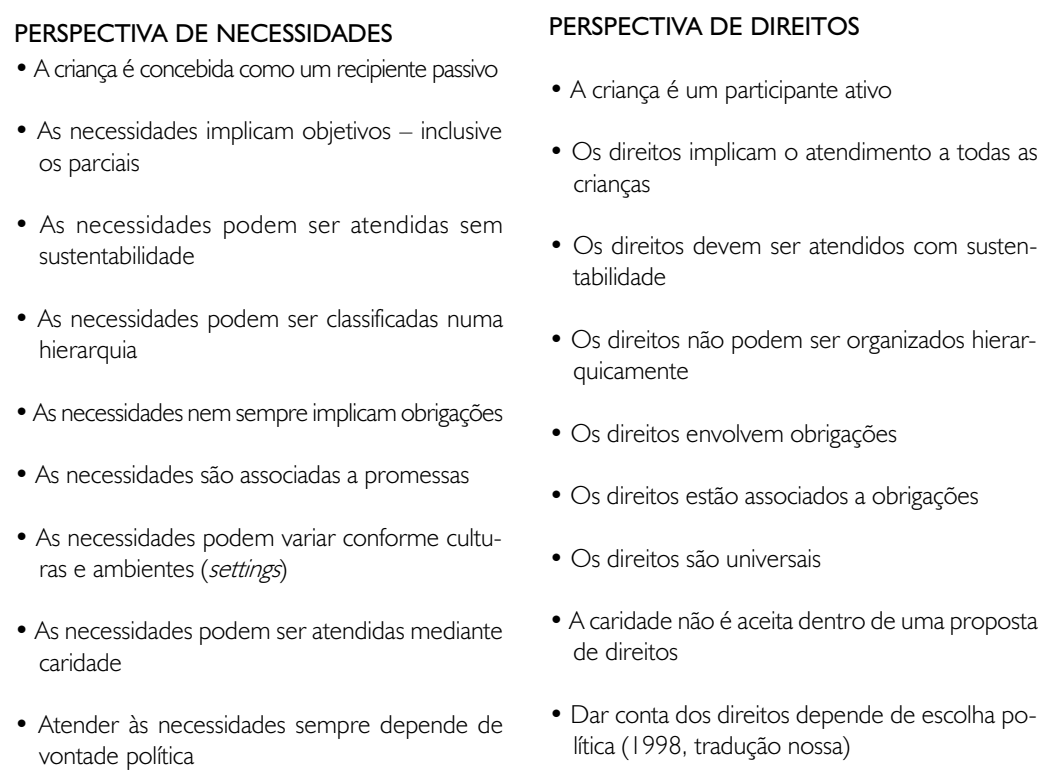

- A criança é concebida como um recipiente passivo

- As necessidades implicam objetivos - inclusive os parciais

- As necessidades podem ser atendidas sem sustentabilidade

- As necessidades podem ser classificadas numa hierarquia

- As necessidades nem sempre implicam obrigações

- As necessidades são associadas a promessas

- As necessidades podem variar conforme culturas e ambientes (settings)

- As necessidades podem ser atendidas mediante caridade

- Atender às necessidades sempre depende de vontade política

PERSPECTIVA DE DIREITOS

- A criança é um participante ativo

- Os direitos implicam o atendimento a todas as crianças

- Os direitos devem ser atendidos com sustentabilidade

- Os direitos não podem ser organizados hierarquicamente

- Os direitos envolvem obrigações

- Os direitos estão associados a obrigações

- Os direitos são universais

- A caridade não é aceita dentro de uma proposta de direitos

- Dar conta dos direitos depende de escolha política (1998, tradução nossa)

A distinção feita por Jonsson nos parece útil na análise dos programas desenvolvidos em muitos países latino-americanos e do Caribe descritos nos documentos que recebemos. Alguns autores apresentam uma visão geral, em uma série de documentos (Peralta, 1996; Peralta, Gomez, 1998; Peralta, Larraguibel, 1996), realizando uma revisão extensa sobre programas de atenção a crianças pequenas, 
desenvolvidos em vários países latino-americanos. São observados vários avanços e contradições em um mesmo país e entre os vários países. Os principais objetivos parecem ser: combater os efeitos da pobreza e preparar as crianças pequenas para a educação primária. Para atingir esses alvos estão sendo propostas diversas modalidades de programas formais e informais, com diferentes objetivos, denominações e maneiras de serem implementados. Os autores indicam o grande crescimento de programas informais desenvolvidos pela ação conjunta de agências do Estado, grupos comunitários, instituições privadas e/ou fundações. Aparecem aqui claramente as orientações do Banco Mundial e a implementação desses programas geralmente é mantida pelos ministérios de educação ou por outros órgãos responsáveis.

Um exemplo é o Programa Nuestros Niños (Unicef, 1997), administrado conjuntamente pelo município de Montevidéu (Uruguai) e pelo Unicef, com participação ativa da comunidade. O programa colombiano Niño a Niño, desenvolvido pela Corporación de Investigaciones para el Desarrollo - Cinde (Arango, 1993) -, constitui outro exemplo. Seus componentes básicos são as visitas domiciliares feitas por um educador para aconselhar os pais sobre a educação de seus filhos, com ênfase em temas como saúde, higiene e nutrição. A Cinde também está desenvolvendo programas similares no Chile (Cinde, 200 I; Peralta, 1998); no mesmo país, o Centro de Investigación e Desarrollo de la Educación - Cide (1996, 1996a) desenvolve programa em moldes semelhantes: Padres e Hijos.

Um programa ao qual se faz bastante menção é o Educa tu Hijo, criado e desenvolvido pela comunidade cubana (Cuba, 1996; Valdés et al., 1994). As atividades educacionais são dirigidas por profissionais, pais e crianças em jardins e locais públicos, duas ou três vezes por semana, ao longo de todo o ano. O programa já atende $98 \%$ da população pré-escolar, mas as mães trabalhadoras geralmente não podem participar das atividades. No Chile, a Junta Nacional de Jardines Infantiles Junji ( 1993) - está desenvolvendo um programa semelhante; a equipe de intervenção é composta de educadores e técnicos que orientam os pais a estimularem e melhorarem a saúde e nutrição de seus filhos, além de avaliarem a eficácia das ações. No Chile, também, a Fundação Integra $(1997,2000)$ desenvolve programas dirigidos às populações mais pobres, além de diferentes modalidades de programas nos centros associados com os quais interage. Os relatórios de Cuba e do Chile fazem uma avaliação positiva desses programas.

Outra forma de programa de atenção infantil é aquela realizada por veículos de comunicação como rádio e televisão. No Chile, existem programas televisivos como o Jardín infantil a la distancia, o Aprendiendo juntose o Jardín infantil a domicilio, 
todos desenvolvidos pela Junji. Programas similares podem ser encontrados no México e Peru.

Os programas, grosso modo, procuram situar-se numa perspectiva de direitos enquanto o discurso e os documentos do Banco Mundial, em regra, os atrelam mais a uma perspectiva de necessidades.

Os países do bloco latino-americano apresentam uma desigualdade social tão marcante que influencia drasticamente a forma como as políticas são concebidas e os programas implementados. As políticas são justificadas, basicamente, como meio de intervenção social para ajudar aqueles que necessitam e para evitar eventuais conseqüências anti-sociais. Dessa forma, os programas de intervenção guardam o ranço, construído historicamente e que sobrevive ao longo de séculos, da necessidade de proteger a sociedade dos efeitos da pobreza e de prevenir a marginalização (Dahlberg, Asén, 1994; Dahlberg, Moss, Pence, 1999). É evidente que as dimensões sociais da pobreza e da indigência, encontradas em muitos países em desenvolvimento e até em países desenvolvidos, certamente exigem algumas políticas focais que aliviem tais efeitos em crianças que vivem em condições de grande privação. Contudo, essas políticas efetivamente promoverão inclusão se assentadas na perspectiva do direito. De acordo com o que foi apontado por Demo (2000), é essencial considerar inclusive o direito à sobrevivência. As principais políticas para educação e cuidado infantil não podem porém ser reduzidas a uma ajuda aos que necessitam, a uma educação para submissão e exclusão, pois essas políticas podem colaborar para a construção de uma cidadania assistida e tutelada. Elas devem ter como objetivo a promoção da autonomia e o exercício da cidadania, para que esta seja responsável e competente. Uma educação de boa qualidade, como um direito, é o instrumento básico para alcançar esses objetivos. A educação e o cuidado infantil devem ser propostos como meios de inclusão social, oferecendo condições que permitam a construção de uma cidadania emancipada. Os melhores resultados de uma política eficiente contra a pobreza são obtidos, justamente, quando os assistidos alcançam um estado no qual são emancipados da ajuda (Demo, 2000) e, para tanto, o indivíduo deve ter o direito à educação e ao aprendizado contínuo.

Além da perspectiva do direito, a qualidade constitui um aspecto fundamental na discussão dos programas e diferenças entre países desenvolvidos e em desenvolvimento. $\bigcirc$ atendimento com critérios e padrões de qualidade passa necessariamente por um discurso que prioriza o investimento na formação de pessoal. Essa questão vem acompanhada de avanços cientíicos e estudos na área. Estudos internacionais, como o que foi recentemente publicado por Dahlberg, Moss e Pence (1999), elogiam particularmente a qualidade promovida pelas políticas desenvolvi- 
das na Dinamarca e na Itália, com especial ênfase na experiência de Reggio Emilia (Katz, 1993; Malaguzzi, 1993). A Comunidade Européia exige de seus professores/ educadores infantis título universitário e investe seriamente na sua formação com um currículo extremamente diversificado, que, freqüentemente, inclui música, arte, teatro e literatura, conforme evidenciado em investigação de Bertram, Heaslip e Pascal ( 1991) em I I países europeus. As experiências recentes, que incluem professores com essa formação, têm sido tão boas que inspiraram uma revisão no currículo de professores e alunos de nível fundamental e médio nos países escandinavos, levando à formulação de propostas pedagógicas unificadas, para a educação da criança de 0 a 16 anos. A experiência da Dinamarca, que atende praticamente a toda a demanda, faz grandes investimentos para a melhoria da formação profissional dos educadores e de todos os profissionais envolvidos, enfatizando a necessidade de uma formação específica. A Reggio Emilia dá importância especial ao contexto educacional para a produção de uma proposta pedagógica efetiva, com especial relevo à organização semiótica do espaço. Outro aspecto extensa e intensamente apontado é a fundamental importância da participação ativa da família e da comunidade nas instituições de educação infantil.

No que se refere aos novos conhecimentos, embora as pesquisas venham contribuindo para a construção de uma pedagogia da educação infantil, nos países em desenvolvimento (Rocha, 1999), a teoria e o discurso ainda estão bem distantes da realidade prática, sendo inclusive a inserção desses conhecimentos mais rápida nas instituições que atendem às camadas altas e médias da população. Aquelas que atendem às populações de baixa renda possuem maiores dificuldades em atingir padrões mínimos de qualidade.

Uma das discrepâncias maiores diz respeito à formação das pessoas responsáveis pela educação das crianças pequenas. As políticas, fundamentadas em concepções compensatórias, geralmente propõem o uso de mão-de-obra barata, explorando o trabalho de mulheres de baixa escolaridade. Baseiam-se na suposição de que, por meio de suas "habilidades naturais", elas podem realizar a prática educacional com crianças pequenas, mesmo na ausência de formação prévia e com reduzida supervisão em serviço. Esse fato é ainda mais problemático quando se considera o segmento creche, uma vez que para o período de 0 aos 3 anos ainda prevalecem formas de atendimento fragmentadas, pouco flexíveis e segregadas, refletindo uma cisão entre as ações de cuidar e educar, conforme aponta Haddad (1997). Além disso, nessa faixa etária, é ainda mais recente o desafio de educar/ cuidar coletivamente de crianças, exigindo criatividade na superação, seja de antigos modelos, seja ao adotar novas formas de educar as crianças mais velhas. 


\section{CRECHE DOMICILIAR/MÃE-CRECHEIRA COMO "ALTERNATIVA"}

A educação e o cuidado infantil devem funcionar como organismo multifacetado embutido na sociedade civil, engajado num trabalho pedagógico construtivo, que busca promover a solidariedade e a cooperação, além de servir como um "lugar" para uma prática emancipadora e democrática (Dahlberg, Moss, Pence, 1999, p.84). Como afirmam várias pesquisas internacionais, a qualidade está atrelada à formação profissional dos que atuam na área, sendo um critério aceito internacionalmente ao menos 12 anos de escolaridade (Bertram, Heaslip, Pascal, |99|), além de supervisão e formação em serviço.

A adequação das propostas recentes do Banco Mundial para a população infantil de baixa renda deve ser analisada tendo como base esses critérios. Os técnicos propõem programas de atendimento domiciliar informal de baixo custo para as camadas pobres, que empregam as próprias mães em seus lares. A capacitação das mães é feita, geralmente, por rápido treinamento em serviço. Young ( 1996) fornece um exemplo desse tipo de programa: o Projeto Integrado de Desenvolvimento Infantil da Bolívia, em que os educadores recebem 40 horas de treinamento prévio e duas semanas de experiência prática.

Em alguns países, como Brasil, Colômbia, Bolívia e Peru, há um forte incentivo a programas denominados "creches domiciliares" ou "mães-crecheiras". Um exemplo desse tipo é o programa Hogares Comunitarios de Bienestar, da Colômbia (Instituto Colombiano de Bienestar Familiar - ICBF -, 1993, 1993a), realizado em parceria do ICBF, com os ministérios da educação e saúde, o Unicef, um banco e outros institutos, envolvendo ainda participação comunitária, com supervisão permanente no local e a distância. Os documentos apontam como objetivos: melhoria das condições de vida da população; fortalecimento da unidade familiar; melhoria do estado nutricional e de saúde da criança e promoção do desenvolvimento humano das pessoas que participam do programa e o executam.

A proposta de atendimento domiciliar não é nova. Ela traz de volta discursos e práticas típicos dos programas considerados compensatórios, inicialmente desenvolvidos nos Estados Unidos, nos anos 60, como parte de um projeto extenso e bastante difundido: o Head Start. Tais programas tiveram início pela observação de que crianças vindas de famílias ricas e cultas, ao ingressarem na escola, já traziam um "currículo oculto" desenvolvido, constituído de amplo repertório e de séries de habilidades que facilitavam seu sucesso na escola. $O$ repetido fracasso escolar de crianças advindas de famílias pobres e de "grupos minoritários" (um eufemismo usado para se referir a índios, latinos e negros) era atribuído ao fato de que elas não 
teriam tido a oportunidade de adquirir um "currículo oculto" devido à precariedade do ambiente familiar no qual viviam. Para superar tais déficits, diversos programas pedagógicos de educação e cuidado infantil foram concebidos para proporcionar a essas crianças uma entrada na escola com aptidão (head start), intensificando suas possibilidades de competir e ter sucesso na aprendizagem.

Nos anos 70, programas dessa ordem foram disseminados nos "países em desenvolvimento", em geral, como um modo de reduzir os efeitos da pobreza. Suas limitações tornaram-se evidentes. A implementação nesses países foi precária e instável devido à insuficiência dos investimentos e ao treinamento reduzido às pessoas envolvidas no seu planejamento e execução, prestando-se mais à manutenção do oferecimento de serviços com qualidades desiguais como instrumento a um duplo processo de exclusão: o de crianças e mulheres de camadas pobres (Rosemberg, 1999a).

Muitos autores têm criticado os programas que se apresentam como solução alternativa do Estado para a expansão das vagas em educação infantil. Rosemberg ( 1989) faz uma análise crítica dos argumentos utilizados pelos governos e discurso oficial para legitimar esses programas, em especial o de creches domiciliares. Eis alguns aspectos importantes dessa crítica:

- $O$ adjetivo alternativo está mal empregado na medida em que, geralmente, os programas possuem um caráter propagandístico, são emergenciais e provisórios, deixando de lado aspectos educativos e identificando-se muito mais com função de guarda.

- Os programas têm caráter de atendimento familiar que se opõe ao institucional. Além da crença de que a mulher e a família são as que devem educar a criança, essa proposta não se sustenta internamente, uma vez que as crianças são atendidas por pessoas que não compõem o seu círculo familiar. "A creche domiciliar no contexto da atuação do estado nos parece uma tentativa de conciliação entre o velho e o novo, aceitando apenas parcialmente que a criança pequena não seja socializada exclusivamente por sua família" (p. 220).

- No discurso do baixo custo dessa modalidade de programa, que pressupõe ser a instituição de educação infantil um empreendimento caro, não se consideram os altos custos indiretos dos programas "alternativos" e o prejuízo de uma baixa qualidade de serviços para as crianças.

- A deterioração do sentido atribuído ao conceito "participação da comunidade" embutido nesses programas, pois apesar de existirem propostas de 
co-gestão, na prática, a população local simplesmente executa as atividades planejadas pela equipe técnica local ou central.

Rosemberg desconstrói assim o argumento de que esses programas estejam assentados na perspectiva dos direitos.

Franco (1989) realizou um estudo sobre seis programas alternativos brasileiros e aponta aspectos positivos e negativos relacionados a eles. A maioria dos programas avaliados apresentou baixo custo e pouca qualidade; apenas um programa apresentou baixo custo, com recursos modestos e boa qualidade. Como aspectos negativos, foram verificados problemas relativos à falta de provisão de alimentos para as crianças. Além disso, as mães que cuidam das crianças são mal remuneradas e a participação da comunidade, geralmente, só é feita na forma de donativos. Para concluir, a autora afirma que "se prevalecer a expansão do sistema às expensas de uma exagerada minimização dos custos, as creches-lares podem se tornar uma solução formal, mas não efetiva, aos problemas que se dispõem a resolver" (p. 208). Ela considera que diante da magnitude do problema assistencial da criança carente e da situação econômica do país, a definição de alternativas satisfatórias deve considerar uma otimização dos recursos disponíveis e não os critérios de qualidade do atendimento e de custos necessariamente os mais baixos. Além disso, o modelo deve atender de forma completa às condições e necessidades locais.

A Organização Mundial para a Educação - OMEP (Simão, Morettini, 1996) elaborou documento de avaliação de um programa de creches domiciliares, implantado por ela, no Município de Campo Grande, Estado do Mato Grosso do Sul. Como muitas mães de bairros pobres deixavam seus filhos em casas de vizinhos, buscou-se sistematizar a solução encontrada pela comunidade. Concluiu-se que os programas de creche domiciliar não podem ser encarados como uma solução para problemas sociais, mas verificou-se que eles foram relevantes nas comunidades em que estavam inseridos.

Fonseca (1998) afirma que os programas com participação comunitária seriam uma forma de dividir os gastos escolares entre governo e familiares. Dessa maneira, a descentralização contribui para a política de recuperação de custos e para a redução do papel do Estado na oferta dos serviços educacionais.

\section{CRECHES E PRÉ-ESCOLAS: A ÚNICA ALTERNATIVA DEFENSÁVEL?}

As considerações sobre programas de creche domiciliar levam-nos a indagar se as instituições creche e pré-escola são as únicas formas desejáveis de atendimen- 
to à criança pequena e de compartilhar a educação e cuidado com a família. Nesse caso, faz-se necessário retomar a articulação entre os indicadores sociais e de escolaridade citados, a história de expansão do atendimento à criança nos países da América Latina e os discursos que a fundamentaram. Essa retomada nos permitirá responder que sim e não.

Para nós, é evidente que esses programas constituem, ao final, alternativas para as famílias que não encontram, no sistema formal, vaga, apoio e suporte para a educação e cuidado dos filhos. Cabe-nos questionar, contudo, se essas famílias fariam uma escolha por tais serviços em detrimento do atendimento em creches e pré-escolas. Na Finlândia, por exemplo, um terço do atendimento às crianças é realizado em creches domiciliares e os pais o fazem por escolha (Stakes, 200 I). Entretanto, a cultura é extremamente diferenciada, refletindo-se no nível de escolaridade, nas condições de moradia, na estrutura e no funcionamento das instituições, no sistema de benefícios para a gestante e a mãe, no investimento realizado pelo governo.

Nos países da América Latina, como demonstram as pesquisas, os programas ditos "alternativos" acabam por reforçar a exclusão social de populações infantis provenientes de camadas pobres. Cabe lembrar que essa política faz parte de uma política maior, em que nem mesmo as instituições formais, e, principalmente, as creches conseguiram cumprir a função de inclusão, conforme demonstram pesquisas. Na verdade, há que se buscar a fundamentação dos discursos que norteiam a proposta desses programas, com base em aspectos macrossociais e culturais.

Os seres humanos têm uma enorme plasticidade e seus filhos podem se desenvolver de várias maneiras nos ambientes culturais e físicos mais diversos. De fato, esses ambientes são organizados, geralmente, de acordo com as expectativas que os pais têm a respeito de seus papéis e das habilidades infantis atuais e futuras (Amorim, Vitoria, Rossetti-Ferreira, 2000; Rossetti-Ferreira, Amorim, Silva, 2000). As mães e as famílias, por sua vez, também apresentam várias demandas. Elas solicitam diversos tipos de apoio para cuidar de seus filhos pequenos e educá-los. Essa diversidade de situações exige sempre soluções novas e criativas, capazes de responder às especificidades locais, que podem ser físicas, sociais ou culturais.

No caso de muitos países desenvolvidos, a creche domiciliar é efetivamente uma alternativa de educação e cuidado tanto para os pais como para o Estado. Fundamentados na perspectiva do direito e de um Estado de Bem-Estar Social, esses serviços não constituem categorias diferenciadas de qualidade do atendimento.

No caso de países da América Latina, não se trata de negar propostas ditas alternativas, mas de redefini-las e compreendê-las de modo crítico. Em relação ao 
atendimento às crianças pequenas, é importante que exista uma variedade de projetos, capaz de dar conta da diversidade cultural presente nesses países. Entretanto, essas propostas devem assumir muito mais o caráter de complementaridade em relação às ações educativas do que de alternativas ou substitutivos a elas. A superação de uma política assentada na perspectiva de necessidade e dos processos de exclusão só ocorrerá mediante um maciço investimento que de fato promova a qualidade do atendimento em instituições de educação infantil e não no desvio desse investimento para programas com qualidade questionável.

Por último, gostaríamos de acentuar a complexidade do tema. Ele demanda uma abordagem sistemática utilizada por especialistas de várias áreas de conhecimento, assim como novas pesquisas e considerações, em especial, sobre o financiamento dos programas oficiais. As políticas baseadas na análise dos vários aspectos envolvidos, estabelecidas por investigações sérias e apropriadas, podem certamente contribuir para o desenvolvimento de programas mais relevantes e socialmente mais eficazes.

\section{REFERÊNCIAS BIBLIOGRÁFICAS}

AMORIM, K.; VITORIA, T.; ROSSETTI-FERREIRA, M. C. Rede de significações: perspectiva para análise da inserção de bebês na creche. Cadernos de Pesquisa, n. 1 09, p. I I 5- |44, mar. 2000 .

ARANGO, M. International center for education and human development. In: COCHRAN, M. (org). International handbook of child care policies and program. USA: Greenwood Press, 1993. p. 107-123.

ARRIAGADA, I. Familias latinoamericanas: convergencias y divergencias de modelos y políticas. Revista da Cepal, n. 65, p. 85-103, 1998.

BANCO INTERAMERICANO DO DESENVOLVIMENTO - BID. América Latina frente a la desigualdad. Washington, D.C.: BID, 1998.

Documento de discussão. Washington, D.C.: BID, 2000.

BANCO MUNDIAL. Desarrollo de la primera infancia: invertir en el futuro. Washington, 1996.

BERTRAM, T.; HEASLIP, P.; PASCAL, C. Comparative directory of initial training for early years teachers. U.K: Early Years Working Group, 1991.

BRASIL. Leis, decretos etc. Estatuto da Criança e do Adolescente - ECA. Lei n. 8.069/90. Lei de Diretrizes e Bases da Educação Nacional- LDB. Lei n. 9.394/96. 
. Plano Nacional de Educação: parecer e substitutivo do relator deputado Nelson Marchezan - Pls n. 4. I55/98 e 4.173/98. Brasília: Câmara dos Deputados, 1999.

BRATEN, S. (org.). Intersubjective communication and emotion in early ontogeny. U.K.: Cambridge University Press, 1998.

BRONFENBRENNER, U. Toward an experimental ecology of humam development. American Psychologist, v. 32, p. 513-531, 1977.

CAMPOS-DE-CARVALHO, M. I., MINGORANCE, R. C. Zonas circunscritas e ocupação do espaço por crianças pequenas em creche. Revista Interamericana de Psicologia, v. 33, n. 2, p. 67-89, 1999.

CAMPOS-DE-CARVALHO, M. I.; ROSSETTI-FERREIRA, M. C. Importance of spatial arrangements for young children in day care centers. Children's Enviroments, v. 10, n. I, p. 19-30, 1993.

CENTRO DE INVESTIGACIÓN Y DESARROLLO DE LA EDUCACIÓN - Cide. Documento de discussão, n. 2: Formación de adultos para el trabajo con niños: la experiencia del Programa Padres y Hijos, 1996.

. Documento de discussão, n. 3: Transferencia de innovaciones educativas: el caso del Programa Padres y Hijos, n. 3, 1996 a.

COCHRAN, M. (org.). International handbook of child care policies and programs. USA: Greenwood Press, 1993.

COMISSÃO ECONÔMICA PARA AMÉRICA LATINA E CARIBE - Cepal. América Latina: tipos de hogar y familia según el género del jefe de hogar. In: ARRIAGADA, I. Famílias latinoamericanas: convergências y divergencias de modelos e políticas. Revista da Cepal, v. 65, p. $88,1994$.

Panorama Social da América Latina: anexo estatístico. Chile, 1998. Diponível em: <http://www.eclac.cl/espanol/Publicaciones/ps98/cuadros/anexo.htm>, 1998.

CORPORACIÓN DE INVESTIGACIONES PARA EL DESARROLLO. Chile, 200। . Disponível em: <http://www.preal.cl/cordina.htm>.

CUBA. Report of Republic of Cuba to the 45 th International Conference on Public Education. Havana: Ministério da Educación, 1996.

DAHLBERG, G.; ASÉN, G. Evaluation and regulation: a question of empowerment. In: MOSS, P.; PENCE, A. (orgs.). Valuing quality in early childhood services. London: Chapman Publishing, 1994.

DAHLBERG, G.; MOSS, P.; PENCE, A. Beyond quality in early childhood education and care: postmodern perspectives. London: Falmer Press, 1999. 
DEMO, P. Educação pelo avesso: assistência como direito e como problema. São Paulo: Cortez, 2000.

EUROPEAN COMMISSION NETWORK ON CHILDCARE - ECNC. Quality in services for young children. Brussels: European Childcare Network, 1992.

. Quality in childcare services. Brussels: European Childcare Network, 1990.

. Quality targets in services for young children. Brussels: European Childcare Network, $1996 \mathrm{a}$.

. A Review of services for young children in the European Union 1990-1995. Brussels: European Commission Directorate General V, $1996 \mathrm{~b}$.

FONSECA, M. Banco Mundial como referência para a justiça social no terceiro mundo: evidências do caso brasileiro. Revista da Faculdade de Educação, v. 24, n. I, p.37-69, jan.jun. 1998.

FRANCO, M. A. C. Lidando pobremente com a pobreza: análise de uma tendência no atendimento a crianças "carentes" de 0 a 6 anos de idade: 1984. In: ROSEMBERG, F. (org.). Creche. São Paulo: Cortez, 1989. p. 179-216.

FREIRE, P. Pedagogia do oprimido. São Paulo: Paz e Terra, 1970.

FUNDO DAS NAÇÕES UNIDAS PARA A POPULAÇÃO. Situação da população mundial. Lisboa: FNUAP, 1998.

GUIMARÃES, J. L.; PINTO, J. M. A Demanda pela educação infantil e os recursos disponíveis para seu financiamento. (no prelo)

HADDAD, L. A Ecologia do atendimento infantil: construindo um modelo de sistema unificado de cuidado e educação. São Paulo, 1997. Tese (dout.) USP.

FUNDAÇÃO INSTITUTO BRASILEIRO DE GEOGRAFIA - FIBGE. Pesquisa sobre padrões de vida, 1996/7. Brasil, 1997.

FUNDAÇÃO INTEGRA. Primeiro, los niños. Chile: Fundação Integra, 1997.

. Que es integra? Chile: <mww.integra.cl>, 2000.

INSTITUTO COLOMBIANO DE BIENESTAR FAMILIAR. Hogares comunitarios de bienestar: una alternativa de atención al niño. Bogotá, 1993.

Hogares comunitarios de bienestar: un programa para la comunidade. Bogotá, 1993 a.

JONSSON, U. A Rights compared to a needs perspective on ECCD. South Asia: Unicef Regional Office, 1998.

JUNTA NACIONAL DE JARDINES INFANTILES - Junji. Desarrollo de una atención integral pertinente a América Latina. Chile: Primer Simposio Latinoamericano de Educación Parvularia, 1993. 
. Guia de funcionamiento para salas cunas y jardines infantiles. Chile.

KATZ, L. What can we learn from Reggio-Emilia? In: EDWARDS, C.; GANDINI, L.; FORMAN, G. (orgs.). The Hundred languages of children. Norwood, N.J.: Ablex, 1993.

LAUGLO, J. Banking on education and the uses of research. International Journal of Educational Development, v. 16, n. 3, p. 221-233, 1996.

MALAGUZZI, L. For an education based on relationships. Young Children, v. II , n. 93, p. 9-13, 1993.

MIRANDA, M. G. Novo paradigma de conhecimento e políticas educacionais na América Latina. Cadernos de Pesquisa, n. 100, p. 37-48, mar. 1997.

MYERS, R. Early child care and development: a global review. EUA: Unicef, no prelo.

NATIONAL INSTITUTE OF CHILD HEALTH AND HUMAN DEVELOPMENT. The NICHD study of early child care. US Department of Health and Human Service, 1998. OECD.

OLIVEIRA, Z. R. The concept of role unit of analysis of young peers' interactions and cultural learning. In: CHAIKLIN, S. (org.). The theory and practise of cultural-historical psychology. Aarhus: Aarhus University Press, 2001.

OLIVEIRA, Z. M. R.; ROSSETTI-FERREIRA, M. C. Coordination of roles: a theorical methodological perspective for studying human interactions. In: MERCER, N.; COLL, C. (orgs.). Teaching, learning and interaction. Madrid: Ed. P/ del Rio, 1994, v. 3, p. 217-21: Explorations in social-cultural studies.

. O valor da interação criança-criança em creches no desenvolvimento infantil. Cadernos de Pesquisa, n. 87, p. 62-70, nov. 1993.

ORGANISATION FOR ECONOMIC CO-OPERATION AND DEVELOPMENT. Country Note: Early Childhood Education and Care Policy in the United States of America. Disponível em: <www.oecd.org>.

PENN, H. The World's Bank view's of early childhood. London, 2000.

PERALTA, M. V. E. La Crianza de los niños menores de seis años en latinoamérica: un análisis de estudios realizados y propuestas para su continuidad. Chile: Organização dos Estados Americanos, 1996.

PERALTA, M. V. E.; GOMEZ, G. F. La Atención integral de la primera infancia en America Latina: ejes centrales y los desafios para el siglo XXI. Chile: OEA, 1998.

PERALTA, M. V:; LARRAGUIBEL, E. Panorama general sobre el cuidado y la educacion de la primeira infancia en America Latina y Caribe: una aproximación. Petrópolis: Unesco; Orealq, 1996.

PIOTTO, D. C. et al. Promoção da qualidade e avaliação na educação infantil: uma experiência. Cadernos de Pesquisa, n. 105, p. 52-77, nov. 1998. 
PROGRAMA DAS NAÇÕES UNIDAS PARA O DESENVOLVIMENTO. Relatório sobre o desenvolvimento humano: 1999. Lisboa: Trinova, 1999.

ROCHA, H. A. C. A Pesquisa em educação infantil no Brasil: trajetória recente de consolidação de uma pedagogia. Florianópolis: UFSC/NUP, 1999.

ROSEMBERG, F. Creches domiciliares: argumentos ou falácias. In: ROSEMBERG, F. Creche. São Paulo: Cortez, 1989. p.217-235.

. Estado dos dados para avaliar políticas de educação infantil. Estudos em Avaliação Educacional, n. 20, p. 5-57, jul./dez. 1999.

. Expansão da educação infantil e processo de exclusão. Cadernos de Pesquisa, n. 107, p. 7-44, jul. 1999a.

. The World Bank and ECCE policies for the third world: resumo. European Early Childhood Education Research Association, 2000. p. 62.

ROSSETTI-FERREIRA, M. C.; AMORIM, K. S.; SILVA, A. P. S. Uma perspectiva teóricometodológica para análise do desenvolvimento e do processo de investigação. Psicologia: Teoria e Crítica, v. 13, n. 2, p. 28I-293, 2000.

ROSSETTI-FERREIRA, M. C. et al. (orgs.). Os Fazeres na educação infantil. São Paulo: Cortez, 1998.

SIMÃO, I. M. A. R.; MORETTINI, M, T. Programa creches domiciliares: uma experiência em foco. Campo Grande: Omep, 1996.

SOARES, M. C. C. Banco Mundial: políticas e reformas. In: TOMMASI, L. et al. (orgs.). O Banco Mundial e as políticas educacionais. São Paulo: Cortez, 1999. p. 15-40.

STAKES. Taskutieto. Finland: Helsinki, 2001.

UNESCO. Directory of organizations in Latin America and the Caribbean. United Nation Educational, Paris: Unesco, 1996.

UNICEF. Programa nuestros niños. Montevideo: Unicef, 1997.

VALDÉS, M. E. et al. Cuba uma alternativa no formal de educación preescolar. Cuba: Editorial Pueblo y Educación, 1994.

WOLF, L.; SCHIEFELBEIN, E.; VALENZUELA, J. Mejoramiento de la calidad de la educación primaria en América Latina y el Caribe. EUA: Banco Mundial, 1994.

YOUNG, M. E. Desarrollo integral de/ niño en la primera infancia: desafíos y oportunidades. Washington, D.C.: Banco Mundial, 1996. 